\title{
EFFECT OF EMOTIONAL INTELLIGENCE COMPETENCIES ON ACADEMIC PERFORMANCE AMID COLLEGE STUDENTS: A STRATEGIC APPROACH
}

\author{
S. Ramesh \\ Research Scholar, Department of Rural Industries and Management, Gandhigram Rural Institute, \\ Gandhigram, Tamil Nadu, India.
}

\begin{abstract}
Dr H. Samuel Thavaraj
Assistant Professor, Department of Rural Industries and Management, Gandhigram Rural Institute, Gandhigram, Tamil Nadu, India.
\end{abstract}

\section{Dr Well Haorei}

Assistant Professor, Department of Rural Industries and Management, Gandhigram Rural Institute, Gandhigram, Tamil Nadu, India.

\section{Dr D. Ramkumar}

Assistant Professor, Department of Business Administration, Govt. Arts College, Paramakudi, Tamil Nadu, India.

\begin{abstract}
Cognitive ability alone is no longer the highest standard by which companies assess college graduates. Non-cognitive ability, such as emotional intelligence (EI), is an essential skill that distinguishes the potential high-performance students. It is hypothesized that high academic performing students will also display more EI levels than students with more modest academic achievement. The present study aims to review the studies conducted across the globe to explore the impact of EI's fundamental components, namely personal and social competencies on academic performance among the college students. The current literature reviews found a growing area of research into EI's necessary competencies and its relationship with academic performance among the students. The study reveals that a high level of personal and social competencies results in increased academic performance and vice versa. Research work done by various researchers shows a positive and significant relationship exists between the EI competencies (personal and social competencies) with the academic performance of the college students.
\end{abstract}

KEYWORDS: Emotional Intelligence, Academic Performance, College students, Personal competencies, Social competencies. 


\section{INTRODUCTION}

Authors have stated that as well as or better than IQ, emotional intelligence predicts success at work, at college, and in relationships. At present, little research exists to support or disprove this dispute (Barchard, 2003). EI entails two extensive competencies, namely personal competencies and social competencies. The personal competencies include self-awareness, self-regulation and selfmotivation, whereas social competencies include social awareness and social skills. Daniel Goleman claims that our thought of social astuteness is inadequate and that our emotional state plays a significant role in cognitive, managerial, and individual advancement (Perloff, 1997).

The EI capabilities play a significant part in envisaging accomplishment of an individual (The Consortium for Research on Emotional Intelligence in Organizations, 1998) in all areas of an individual. Emotional intelligence is a kind of non-cognitive intelligence that comprises the ability to understand one's own and others' emotions, distinguish between them, and use the information to guide one's feelings and behaviour (Mayer \& Salovey, 1993).

The capacity to observe, practice, recognize, and regulate emotions refers to emotional intelligence (EI). The growing understanding that mental capacity contributes to only a trivial volume of the inconsistency seen in substantial life outcomes has flickered attention in EI and associated concepts (Cherniss et al., 2016).

Goleman defined emotional competence as an erudite capability based on emotional intelligence that results in success (Goleman, 1998). Competencies permit a person to establish smart use of their emotions to be creative in managing themselves and interrelating with others (Boyatzis et al., 2000).

\section{METHODS}

An orderly appraisal of double peerreviewed published research work was navigated to summarise the universal information on the influence of EI competencies on the academic performance amid college students. A systematic review of peerreviewed publications in SCOPUS, Education Resources Information Center (ERIC) and Google Scholar databases was searched for relevant studies while emphasizing literature of most significant relevance to the research objective.

\section{SELF-AWARENESS ON ACADEMIC PERFORMANCE}

(Arshad et al., 2015) After many behavioural and educational issues emerged, the study examined self-esteem and academic performance among university students. An essential association among self-esteem and academic performance was identified. A substantial variance was detected among the self-esteem and academic performance scores, suggesting that students have high academic performance scores with high selfesteem ratings.

(Neff et al., 2005) The studies explored the relationship between self-compassion, academic achievement expectations, and coping among undergraduates with perceived academic failure. In instances of loss, self-compassion includes being kind to oneself, perceiving one's experiences as part of the more significant human experience, and keeping negative emotions in mindful consciousness. Self-compassion was positively correlated with mastery goals and negatively associated with success goals, a relationship that was influenced by less fear of failure, and the greater self-compassionate person perceived competence.

(Honicke \& Broadbent, 2016) This analysis summarizes 12 years of research on the link between academic self-efficacy and university students' academic success and established cognitive and motivational factors that explain this connection. The study found that academic self-efficacy was abstemiously associated with the academic achievement of the students. Several mediating and moderating variables, including effort control, indepth processing strategies and target orientations, were established.

(Lane et al., 2004) The study discovered the relations between self-efficacy, self-esteem, performance accomplishments, and academic performance. Correlation findings showed significant relationships between self-efficacy and self-esteem. Multiple regression findings showed that the relationship between performance achievements and academic performance was mediated by self-efficacy. The results support the predictive effectiveness of tests of self-efficacy in educational environments.

(Zajacova et al., 2005) The combined impacts of the academic self-efficacy and tension on the academic performance of non-traditional, college freshers are explored in this paper. The findings indicate that academic self-efficacy is a more robust and reliable indicator of academic performance than stress.

(Joseph, Thavaraj, \& Leo, 2020) The research paper explores the impact of online learning on the academic performance of university students. For the academic year 2019-20, the students were subjected to online learning via video lectures on behalf of COVID 19 and its subsequent announcement on Lockdown by the Government of India's competent authorities. The study focused on understanding the effect on online learning environments' academic performance and the factors that lead to them and their ability to cope with stress due to this sudden outbreak. The findings of the study showed that online learning model has a substantial effect on academic success. 
(Lane \& Lane, 2001) In an academic context, the research aimed to explore the predictive efficiency of self-efficacy. The current study results indicate that in an educational setting, self-efficacy has some utility that influences the students' academic performance.

\section{SELF-REGULATION AND SELF- MOTIVATION}

(Zimmerman, 2000) Self-efficacy beliefs were found to be adaptive to subtle shifts in students' performance background, interconnect with selfregulated erudition progressions, and arbitrate the academic achievement of students.

(Hen \& Goroshit, 2014) Academic procrastination has been regarded as an impediment to the academic achievement of students. Study results indicate that it is connected to minor levels of self-regulated learning and self-efficacy in the academe and is associated with advanced anxiety and ailment levels. The findings exhibited that EI's ancillary impact was more significant in locomotor disability (LD) students than in non-locomotor disability (NLD) students on academic deferment and GPA.

(Kandemir, 2014) The study aims to determine how, in the regression model, the measured variables for the study of self-regulation, self-efficacy, life satisfaction, confidence, and other expressive variables stated in the associated literature on academic postponement explain the behaviour of intellectual delay. It is found that academic procrastination is predicted by the regression model and have a significant association on academic success.

(Ramesh \& H. Samuel Thavaraj D, 2016) The study aims to define the level of emotional intelligence of students and the degree to which emotional intelligence affects students' academic achievement. The study results indicate that all competencies in emotional intelligence are at a high level. Emotional memory, emotional control, selfmotivation, empathy, and social skills do not impact students' academic performance in all emotional intelligence dimensions taken for the research.

(Cassady \& Johnson, 2002) In contrast, procrastination was related to academic performance only during the final examination. An investigation of the association between the emotional factor of test nervousness and academic performance exposed that higher examination performance was usually associated with moderate levels of physiological arousal. The findings were consistent with test nervousness intellectual assessment and information dispensation models support the conclusion that cognitive test nervousness has a significant impact on academic performance.

\section{SOCIAL AWARENESS AND SOCIAL SKILLS}

(Turner et al., 2009) It has been consistently shown that parenting styles relate to different results, such as behavioural problems and academic performance. The study examined the relationships between authoritative parenting style, academic performance, self-efficacy, motivation for achievement among college students, and examining components of self-determination. Results showed that authoritative parenting affects college students' academic performance, and academic performance is predicted by intrinsic motivation and self-efficacy.

(Joseph, Thavaraj, \& Arooran, 2020) The study was designed to investigate the relationship between university students' academic performance during the Covid-19 lockdown era and the influence of emotional intelligence (EI). It identifies the causes of emotional intelligence that influence students' academic performance and explores their impact on the overall emotional level. Emotional intelligence's dominant determinants that affect academic performance are narrated with the aid of factors analysis in emotional stability, relationship management, education aspiration, and locus of control.

(Mohzan et al., 2013) The research discovers the effect of emotional intelligence on academic performance among students in University. The conclusions of the study indicate that there is a high degree of emotional intelligence among the participants. Two domains of the Emotional Intelligence examined are positively correlated with academic achievement among the students.

(Reney \& Thavaraj, 2016) This research aimed to test the relationships between undergraduate engineering students in Trivandrum, India, among emotional intelligence, perceived anxiety, and enthusiasm to learn, education strategies, and academic performance. The findings indicate that there is a compelling positive association between emotional intelligence, perceived stress and desire to learn and academic success.

\section{CONCLUSION}

The above reviews of previous studies exhibit that emotional intelligence competencies have a more substantial influence on college students' academic performance. As the new education policy of the Indian government focuses on skill-based learning, it is necessary to concentrate on the emotional intelligence competencies at the early educational level. The EI competencies can be developed, and the individual will have more clarity in choosing the career. 


\section{REFERENCES}

1. Arshad, M., Muhammad, S., \& Mahmood, K. (2015). Self-Esteem \& Academic Performance Among University students. Journal of Education and Practice.

2. Barchard, K. A. (2003). Does Emotional Intelligence Assist in the Prediction of Academic Success. Educational and Psychological Measurement. https://doi.org/10.1177/0013164403251333

3. Boyatzis, R., Goleman, D., \& Rhee, K. (2000). Clustering competence in emotional intelligence: Insights from the Emotional Competence Inventory (ECI). In Handbook of Emotional Intelligence.

4. Cassady, J. C., \& Johnson, R. E. (2002). Cognitive test anxiety and academic performance. Contemporary Educational Psychology.

https://doi.org/10.1006/ceps.2001.1094

5. Cherniss, C., Roche, C., \& Barbarasch, B. (2016). Emotional Intelligence. In Encyclopedia of Mental Health: Second Edition. https://doi.org/10.1016/B978-0-12-3970459.00207-X

6. Goleman, D. (1998). BEST OF HBR: What Makes a Leader? Harvard Business Review.

7. Hen, M., \& Goroshit, M. (2014). Academic Procrastination, Emotional Intelligence, Academic Self-Efficacy, and GPA: A Comparison Between Students With and Without Learning Disabilities. Journal of Learning Disabilities. https://doi.org/10.1177/0022219412439325

8. Honicke, T., \& Broadbent, J. (2016). The influence of academic self-efficacy on academic performance: A systematic review. In Educational Research Review. https://doi.org/10.1016/j.edurev.2015.11.002

9. Joseph, D. C. S., Thavaraj, D. H. S., \& Arooran, D. G. T. T. (2020). Determinants of Emotional Intelligence and Its Impact: An Empirical Research among University Students during the Covid-19 Lockdown Period in Coimbatore. International Journal of Advanced Science and Technology, 29(7), 5293-5301.

10. Joseph, D. C. S., Thavaraj, D. H. S., \& Leo, M. (2020). Virtual Learning Subteleties And Coping with Stress Among University Students During Covid 19 Lockdown Period: A Structural Equation Model Approach. International Journal of Future Generation Communication and Networking, 13(3), 2143-2154.

11. Kandemir, M. (2014). Reasons of Academic Procrastination: Self-regulation, Academic Selfefficacy, Life Satisfaction and Demographics Variables. Procedia - Social and Behavioral Sciences. https://doi.org/10.1016/j.sbspro.2014.09.179

12. Lane, J., \& Lane, A. (2001). Self-efficacy and academic performance. Social Behavior and Personality. https://doi.org/10.2224/sbp.2001.29.7.687

13. Lane, J., Lane, A. M., \& Kyprianou, A. (2004). Self-efficacy, self-esteem and their impact on academic performance. Social Behavior and
Personality.

https://doi.org/10.2224/sbp.2004.32.3.247

14. Mayer, J. D., \& Salovey, P. (1993). The intelligence of emotional intelligence. In Intelligence. $\quad$ https://doi.org/10.1016/01602896(93)90010-3

15. Mohzan, M. A. M., Hassan, N., \& Halil, N. A. (2013). The Influence of Emotional Intelligence on Academic Achievement. Procedia - Social and Behavioral Sciences. https://doi.org/10.1016/j.sbspro.2013.07.095

16. Neff, K. D., Hsieh, Y.-P., \& Dejitterat, K. (2005). Self-compassion, Achievement Goals, and Coping with Academic Failure. Self and Identity. https://doi.org/10.1080/13576500444000317

17. Perloff, R. (1997). Daniel Goleman's Emotional intelligence: Why it can matter more than IQ. The Psychologist-Manager Journal. https://doi.org/10.1037/h0095822

18. Ramesh, S., \& H. Samuel Thavaraj D, R. (2016). Impact Of Emotional Intelligence On Academic Achievements Of College Students-A Review. International Journal Of Business Management \& Research, 6(2), 25-30.

19. Reney, S., \& Thavaraj. (2016). Role Of Emotional Intelligence, Perceived Stress, Learning Motivation and Learning Strategies For Academic Performance Of Engineering Students In Trivandrum. International Journal of Informative \& Futuristic Research ISSN: $2347-$ 1697, 3(10), 3683-3690.

20. The Consortium for Research on Emotional Intelligence in Organizations. (1998). The Emotional Competence Framework. The Consortium for Research on Emotional Intelligence in Organizations.

21. Turner, E. A., Chandler, M., \& Heffer, R. W. (2009). The influence of parenting styles, achievement motivation, and self-efficacy on academic performance in college students. Journal of College Student Development. https://doi.org/10.1353/csd.0.0073

22. Zajacova, A., Lynch, S. M., \& Espenshade, T. J. (2005). Self-efficacy, stress, and academic success in college. In Research in Higher Education. https://doi.org/10.1007/s11162-004$4139-z$

23. Zimmerman, B. J. (2000). Self-Efficacy: An Essential Motive to Learn. Contemporary Educational Psychology. https://doi.org/10.1006/ceps.1999.1016 